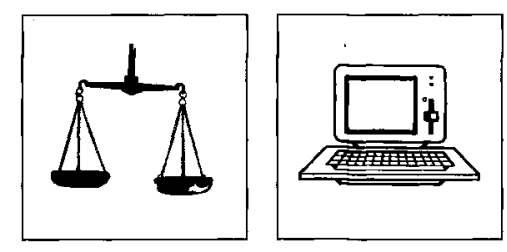

Fehlendes Handbuch und Mängelgewährleistung

der das Wissen der Lieferantin insoweit zuzurechnen wäre, bei Vorlage der Übernahmebestätigung gewußt hätte, daß diese einer Einschränkung bedurfte (vgl. BGH NJW. 1988, 204, 206 unter II 2 d, bb). Dafür fehlt es jedoch an einer tragfähigen Tätsachengrundlage. Die Übernahmebestätigung führte Bedienungsanleitungen und Benutzerhandbücher nur in pauschaler Form auf. Unstreitig ist auch eine Anzahl von Unterlagen übergeben worden. Wenn einzelne Handbücher gefehlt haben, kann dies ohne weiteres infolge Fahrlässigkeit unbemerkt geblieben sein.

(Eingesandt vom 19. Zivilsenat des OLG Köln.)

\title{
EDV-Einsatz und Steuerrechtshilfe
}

OLG Frankfurt am Main, Beschliß vom 1. Oktober 1990 (6. W 126/90)

\section{Leitsatz der Redaktion}

Durch den Einsatz einer EDV-Anlage (hier: Vornahme umsatzsteuerlicher Berechnungen maschinell mit Hilfe eines EDV-Buchhaltungsprogramms) wird die erlaubnisgebundene Steuerrechtshilfe nicht zu erlaubnisfreier mechanischer Kontierungsarbeit.

\section{Gründe}

Die zulässige Beschwerde hat in der Sache keinen Erfolg. Das Landgericht hat gegen den Antragsgegner zu Recht ein Ordnungsgeld wegen Verstoßes gegen das Unterlassungsverbot der einstweiligen Verfügung vom 11.8.1987 verhängt.

Der Sachverbalt: Maschinelle Vornabme umsatzsteuerlicher Berechnungen mit Hilfe eines EDV-Buchbaltungsprogramms

Mehr als erlaubnisfreie mechanische Kontierungsarbeit

Bereits aufgrund des eigenen Vorbringens des Antragsgegners ist davon auszugehen, daß der Antragsgegner die einstweilige Verfügung mißachtet hat. Denn die eidesstattlichen Versicherungen des Antragsgegners und der Zeugin Z. vom 12.7.1990 (Bl. 112/113 d. A.), die der Antragsgegner in der Beschwerdeschrift ausdrücklich zum Gegenstand seines Vortrages gemacht hat, belegen, daß der Antragsgegner für die X. umsatzstenerliche Berechnungen maschinell mit Hilfe eines EDV-Buchhaltungsprogramms vorgenommen und die so ermittelten Zahlen der X. überlassen hat, die dann die Umsatzsteuervoranmeldung selbst angefertigt hat.

Damit überschritt der Antragsgegner die ihm erlaubte Tätigkeit, da erlaubnisgebundene Steuerrechtshilfe nicht durch den Einsatz einer EDV-Anlage zu erlaubnisfreier mechanischer Kontierungsarbeit wird. Vielmehr sind in einem solchen Fall, wie das Kammergericht in seinem Urteil vom 27.9.1989 (Bl. 125 ff. d. A. Stbg 1989, 228, 229) zutreffend dargetan hat, fachmännische Vorgaben und Wertungen erforderlich; für den Antragsgegner war es nicht damit getan, die Daten der X. in die EDV-Anlage einzuspeisen. Eine steuerliche Willensbildung ist gerade für die Umsatzsteuervoranmeldung unerläßlich. Der Antragsgegner hat jedenfalls nicht vorgetragen, daß er sich auf das rein maschinelle Verarbeiten der Daten beschränkt, die Daten also nicht abschließend und verbindlich vorbereitet habe. Davon kann auch deshalb nicht ausgegangen werden, weil der Antragsgegner den Vortrag der Antragstellerin im Schriftsatz vom 14.9.1990, der Steuerberater S. sei vom Antragsgegner nur als Strohmann gegenüber der X. benannt worden, und dieser sei zudem nicht identisch mit

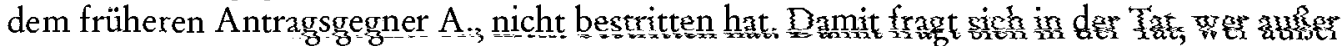
dem Antragsgegner die Daten der X. unter umsatzsteuerrechtlichen Gesichtspunkten bewertet und in die EDV-Anlage eingegeben haben sollte.

Unerheblich ist, daß die X. die Umsatzsteuervoranmeldung als solche gefertigt hat, da entscheidend bleibt, daß die dazu nötigen Vorgaben und Wertungen vom Antragsgegner stammen.

Erforderlichkeit eines „fühlbaren" Ordnungsgeldes

Die Höhe des festgesetzten Ordnungsgeldes begegnet keinen durchgreifenden Bedenken, nachdem der Antragsgegner über einen längeren Zeitraum hinweg dem Unterlassungsverbot zuwider gehandelt hat. Danach ist ein fühlbares Ordnungsgeld erforderlich, um den Antragsgegner zur künftigen Beachtung des Verbotes anzuhalten.

Die Kostenentscheidung beruht auf $\$ 97$ ZPO. 